\title{
Evaluation of the optic nerve and scleral-choroidal-retinal layer with ultrasound elastography in glaucoma and physiological optic nerve head cupping
}

\author{
${ }^{1}$ Özkan Özen, ${ }^{2}$ Murat Atabey Özer, ${ }^{1}$ Alptekin Tosun, ${ }^{2}$ Serkan Özen
}

${ }^{1}$ Department of Radiology, Department of Ophthalmology, Faculty of Medicine, Giresun University, Giresun, Turkey

\begin{abstract}
Aim: To evaluate the strain ratio of the optic nerve and retina-choroid-sclera (RCS) layers in individuals with physiological optic disc cupping (PC) and glaucoma patients using strain elastography. Material and methods: We evaluated 56 eyes of 56 subjects (20 eyes with glaucoma, 19 eyes with PC, and 17 normal eyes). The strain ratio of orbital fat to optic nerve (SROFON) was calculated as the ratio of the optic nerve to intraconal fat tissue and the strain ratio of orbital fat to retina-choroid-sclera (SROFRCS) was calculated as the ratio of RCS layers to intraconal fat tissue. Results: SROFON was 0.92 in the control group, 1.07 in the PC group and 1.6 in the glaucoma group and a statistically significant difference was present between the three groups $(\mathrm{p}<0.05)$. SROFRCS had no statistically significant difference between the three groups. Conclusions: SROFON values could contribute to the differentiation of the patients with glaucoma and PC.
\end{abstract}

Keywords: glaucoma; ultrasonography; strain elastography; strain ratio; optic nerve.

\section{Introduction}

Glaucoma is a chronic, progressive, and asymptomatic anterior neuropathy. In time it can produce damage of the retinal nerve fiber layer (RNFL) and optic nerve, with loss of the related visual field $[1,2]$. A cup/disc (C/D) ratio (ratio of the cup located in the middle of the optic disc to the optic disc itself) higher than 0.4 raises the suspicion of glaucoma. However, in the healthy population this ratio can range between 0.0-0.9 [2]. Physiological cupping (PC) is diagnosed in cases with high $\mathrm{C} / \mathrm{D}$ ratio, normal neuroretinal rim shape, normal RNFL thickness, and normal visual field test [2]. It is difficult to know

Received 28.05.2017 Accepted 20.09.2017

Med Ultrason

2018, Vol. 20, No 1, 76-79

Corresponding author: Özkan ÖZEN, MD. Assistant Professor Giresun University, Faculty of Medicine, Department of Radiology,

Nizamiye mah., Orhan Yilmaz cad., Mumcular sok. 28100, Giresun, Turkey

Phone: 9045431016 00, Fax : 904543101699

E-mail:ozen@doctor.com whether the increase of $\mathrm{C} / \mathrm{D}$ ratio is physiological or due to glaucomatous damage using only biomicroscopic optic disc examination and in practice, further tests are required. Early stages of the $\mathrm{C} / \mathrm{D}$ ratio changes can also be missed on the biomicroscopic optic disc examination during the follow-up of glaucoma progression [3-5].

Although grayscale ultrasonography (US) is a noninvasive method that has been used to evaluate the eye structures for many years, elastography is a new technique and is not used as widely for the orbita and orbital structures as for other organs [6,7].

Strain elastography (SE, quasi-static elastography, qualitative elastography) requires the application of force with the probe (compression-decompression) to ensure the tissue displacement. SE shows a color-coded map reflecting the compressibility of the tissues. The technique compares the tissue of interest with the surrounding tissues and enables a relative evaluation of stiffness. The tissue for which the stiffness will be evaluated and a reference tissue for comparison are selected and the stiffness calculated accordingly. SE enables both qualitative (color-coded map) and semi-quantitative (strain ratio cal- 
culation) evaluation of elasticity [6,8-10]. The basic limitation of this technique is the wide variability of the image and elasticity values as the pressure applied with the probe is examiner-dependent and not standard [11]. The sensitivity of SE vary between $57 \%$ and $92 \%[12,13]$.

The first study showing that ocular structures could be evaluated with elastography was conducted in 2010 [14]. The main problems in the SE evaluation of ocular structures are the possible influence of the small dimension and ocular fluid content. The semiquantitative nature of SE also creates difficulties [12,15]. Various studies have evaluated the $\mathrm{ON}$ using elastographic techniques in glaucoma, optic neuritis, and multiple sclerosis [12,15-18].

In this study our aim was to investigate the ability of SE and of the SR values in differentiating between the optic nerve and scleral-choroidal-retinal (SCR) layers in patients with PC and glaucomatous optic nerve damage.

\section{Material and methods}

\section{Patients}

This prospective study was conducted between April 2015 and May 2016. Local Institutional Ethics Committee approved the study. A written informed consent form was obtained from all patients before the study. We assumed the two eyes of the same subject would be similar. We therefore only evaluated the right eye in each person. We evaluated 56 eyes of 56 subjects (20 eyes with glaucoma, 19 eyes with PC, and 17 eyes with completely normal findings). Subjects with systemic diseases such as hypertension, diabetes mellitus, or peripheral and central nervous system disorders that caused neuronal damage (multiple sclerosis, cranial vasculitis, etc.) were excluded. All patients underwent a routine eye examination as well as Optic Coherence Tomography (OCT) and visual field tests at the eye clinic before elastography. The physician who performed the SE evaluation was blinded to the condition of the individuals prior to the SE investigation.

\section{US technique}

The investigation was conducted using an elastography device (Esaote, MyLab60, Geneva, Italy) with 6-18 $\mathrm{MHz}$ linear probe while the patient was in the supine position with the eyelids closed. The investigation was started using grayscale US (average frequency of the transducer $15 \mathrm{MHz}$ ) and was continued with SE during minimal eye compression. The most appropriate image was selected by performing compression-decompression 5-6 times until the spring turned green indicating the image was suitable for SE evaluation. The values of the strain ratio (SR) of orbital fat to optic nerve (SROFON) and the strain ratio (SR) of orbital fat to retina-cho-

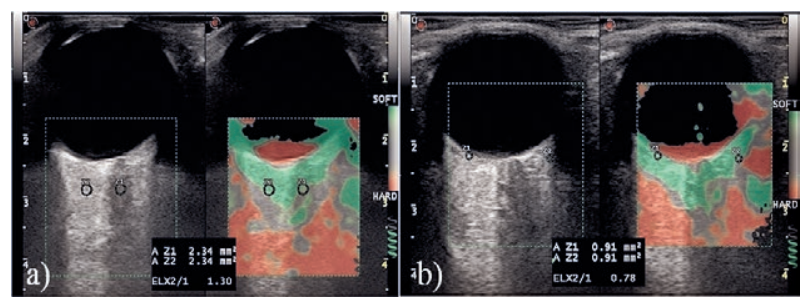

Fig 1. Strain elastography of the eye and the calculation of strain ratio of a) the optic nerve and b) the retina-choroid-scleralayers
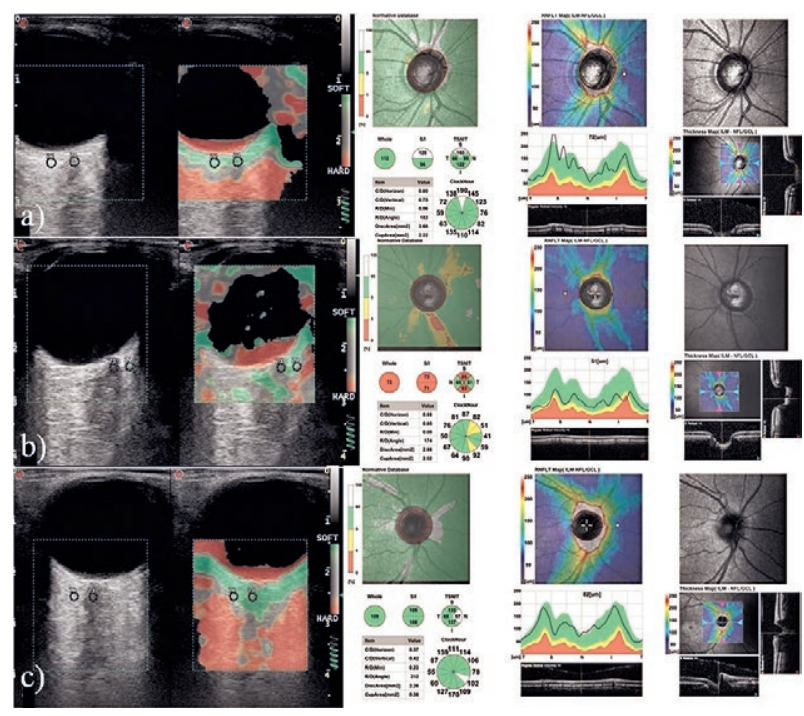

Fig 2. Strain elastography and Optic Coherence Tomography of the right eye in a) 41-year-old normal female patient (SROFON 0.76 , OCT C/D ratio 0.37, and RNFL thickness $109 \mu \mathrm{m}$ ); b) 68-year-old female with physiological optic nerve cupping (SROFON 1.1, OCT C/D ratio 0.80, and RNFL thickness 112 $\mu \mathrm{m}$; c) 53-year-old female patient with glaucoma (SROFON 1.36, OCT C/D ratio 0.88 , and RNFL thickness $72 \mu \mathrm{m}$ ).

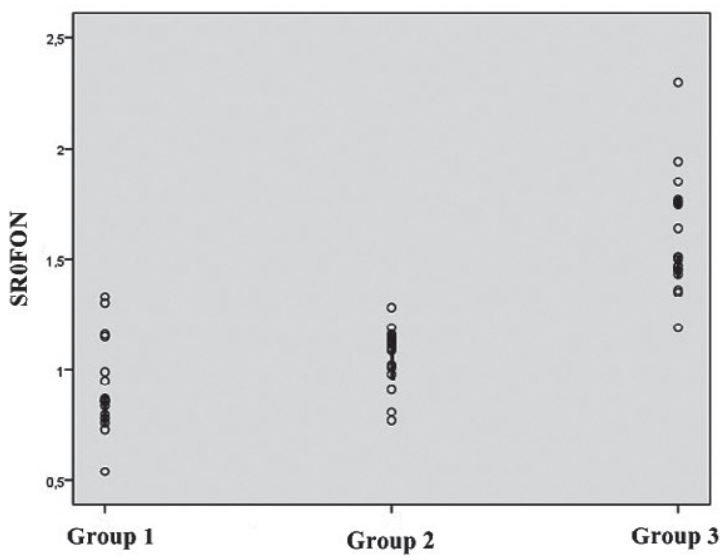

Fig 3. Point distribution graph of SROFON values of the 3 groups (Group 1: Control group, Group 2: PC group, Group 3: Glaucoma group). 
Table I. Optic nerve parameters and elastography results among study groups

\begin{tabular}{llll}
\hline & Control group & PC group & Glaucoma group \\
\hline C/D & $0.32 \pm 0.06$ & $0.753 \pm 0.06^{\mathrm{a}}$ & $0.759 \pm 0.1^{\mathrm{a}}$ \\
RNFL $(\mu \mathrm{m})$ & $111.3 \pm 8.5$ & $111.8 \pm 5.9^{\mathrm{b}}$ & $75.3 \pm 9.3^{\mathrm{c}}$ \\
SROFON & $0.92 \pm 0.208$ & $1.07 \pm 0.12^{\mathrm{a}}$ & $1.6 \pm 0.25^{\mathrm{a}, \mathrm{d}}$ \\
SROFRCS & $1.08 \pm 0.2$ & $1.11 \pm 0.1^{\mathrm{b}}$ & $1.17 \pm 0.2^{\mathrm{b}}$ \\
\hline
\end{tabular}

$\mathrm{C} / \mathrm{D}$, cup/disc; RNFL, retinal nerve fiber layer; SROFON, the strain ratio of orbital fat to optic nerve; SROFRCS, the strain ratio of orbital fat to retina, choroid and sclera; PC, physiological optic disc cup; Values are given as mean \pm SD. ${ }^{\text {a Significantly }}$ higher than the control group $(\mathrm{p}<0.001)$. ${ }^{\mathrm{b}}$ No significant difference with the control group $(p>0.05)$. ${ }^{c}$ Significantly lower than the control group $(\mathrm{p}<0.001) .{ }^{\mathrm{d}}$ Significantly higher than the PC group $(\mathrm{p}<0.001)$.

roid-sclera layers (SROFRCS) were automatically calculated by the device from this selected image. SROFON and SROFRCS values were calculated using the intraconal fat tissue that was most parallel to the optic nerve and to retina-choroid-sclera layers in each eye by selecting the region of interest (ROI), which was $2.34 \mathrm{~mm}^{2}$ for SROFON and $0.91 \mathrm{~mm}^{2}$ for SROFRCS (fig 1).

\section{Statistical analysis}

Data were analyzed using the Statistical Package for Social Sciences (SPSS) software (version 22.0 for Windows). The results were expressed as mean \pm standard deviation (SD) for statistical analysis, Chi square and independent samples $\mathrm{T}$ tests were used and $\mathrm{p}$-value of $<0.05$ was considered statistically significant.

\section{Results}

The mean age was $61.12 \pm 7.1$ years in the control group, $60.11 \pm 8.6$ years in the PC group, and $59.7 \pm 12.1$ years in the glaucoma group and the female/male ratio was $11 / 6,11 / 8$, and $14 / 6$, respectively ( $p>0.05$ ).

The mean $\mathrm{C} / \mathrm{D}$ ratio was statistically significantly higher in the PC and glaucoma groups than the control group $(p<0.001)$. However, there was no difference between the PC and glaucoma groups $(\mathrm{p}>0.05)$. There was no statistically significant difference between the control and PC groups for mean RNFL thickness on OCT $(p>0.05)$ but this value was statistically significantly lower in the glaucoma group comparing withthe $\mathrm{PC}$ and control groups $(\mathrm{p}<0.001)$. Mean SROFON values were highest in the glaucoma group and lowest in the control group. There was a statistically significant difference between the 3 groups $(p<0.001)$. There was no statistically significant difference between the 3 groups for mean ROFRCS values ( $p>0.05$ ) (Table I).

In figure 2 we showed a SE and OCT example from each of the 3 groups. The difference between the 3 groups can be seen more clearly in the point distribution graph of the SROFON values of the control group, PC group and glaucoma group (fig 3).

\section{Discussions}

Elastography, a new US technique, has been largely used for evaluating the prostate, lymph nodes, breast, thyroid, testicles, or kidneys [16]. However, we found only 3 studies in which elastography was used for the study of the optic nerve in glaucoma patients but none of these studies included subjects with PC $[12,15,18]$. Agladioglu et al compared the SROFRCS and optic disk/ optic nerve SR values obtained in glaucoma patients with a control group but found no statistically significant difference [18]. Dikici et al detected higher elasticity values in the glaucoma group [12] and Unal et al found higher optic nerve elasticity values in the glaucoma group than the control group (in these two studies the Shear Wave Elastography [SWE] technique was used) [15]. We obtained similar results regarding the elasticity of the optic nerve in glaucomatous patients.

In a recent published study İnal et al [16] found high optic nerve stiffness using both elastographic techniques, SWE and SE, in multiple sclerosis patients comparing with optic neuritis patients. The optic nerve stiffness in patients with unilateral optic neuritis were higher compared with the normal eye in the study of Batur et al using the Acoustic Radiation Force Impulse (ARFI) technique [17].

Glaucoma causes irreversible retinal ganglion cell damage. This results in fibrosis, especially in the retinal nerve fiber layer and therefore in the optic nerve [19]. Senility and some nervous system disorders can also compromise the optic nerve [20]. We excluded from the study groups the patients with nervous system disorder and there was no significant difference in the mean age of the groups. So, our opinion is that the stiffness values are directly related to glaucoma.

Burgoyne et al [21] conducted an experimental study in monkeys. They found that glaucoma caused connective tissue damage in the optic nerve even in the early stages. This was followed by recovery with scar formation in the extracellular matrix. They stated that such scar formation could lead to stiffness of the optic nerve head. The high ON stiffness in the glaucoma group in our study can be explained by fibrosis.

The highest SROFON values were in the glaucoma group and the lowest in the control group. Our results indicate that elastography provides meaningful values for differentiating PC and glaucoma changes of the optic nerves.

US in one of the most reliable radiologic methods and has no known significant side effects. Orbital Doppler 
US and grayscale US are accepted as safe, easy-to-use and non-ionizing radiation methods. Ocular elastography may cause side effects in the eye and surrounding tissues. It is however safe and quick in evaluating retrobulbar fat tissue and the optic nerve [16].

Our study had certain limitations. The first of these is that SE results can vary by the user. Another limitation is that an eye-specific orbital elastography probe does not exist. We therefore used the most appropriate probe and frequency range for the eye. The third limitation is that the eye has viscoelastic and poroelastic complex compartments. The compression effect may therefore not reach the deep orbital and periorbital structures.

In conclusion, we found that SROFON values differed between PC and glaucoma patients. Elastography may contribute to determining whether changes in subjects with a high $\mathrm{C} / \mathrm{D}$ value are physiological or glaucoma-related. However, these findings need to be supported by other studies using various elastography techniques on a larger patient series.

\section{Conflict of interest: none}

\section{References}

1. Yarmohammadi A, Zangwill LM, Diniz-Filho A, et al. Relationship between Optical Coherence Tomography Angiography Vessel Density and Severity of Visual Field Loss in Glaucoma. Ophthalmology 2016;123:2498-2508.

2. Min KH, Seong GJ, Hong YJ, Kim CY. Optic nerve head topographic measurements and retinal nerve fiber layer thickness in physiologic large cups. Korean J Ophthalmol. 2005;19:189-194.

3. Susanna R Jr, Vessani RM. New findings in the evaluation of the optic disc in glaucoma diagnosis. Curr Opin Ophthalmol 2007;18:122-128.

4. Leung CK. Optical Coherence Tomography Imaging for Glaucoma - Today and Tomorrow. Asia Pac J Ophthalmol (Phila) 2016;5:11-16.

5. Hayreh SS. Pathogenesis of cupping of the optic disc. Br J Ophthalmol 1974;58:863-876.

6. Vural M, Acar D, Toprak U, et al. The evaluation of the retrobulbar orbital fat tissue and optic nerve with strain ratio elastography. Med Ultrason 2015;17:45-48.

7. Lupșor-Platon M, Badea R, Gersak M, et al. Noninvasive Assessment of Liver Diseases using 2D Shear Wave Elastography. J Gastrointestin Liver Dis 2016;25:525-532.
8. Ozkan F, Yavuz YC, Inci MF, et al. Interobserver variability of ultrasound elastography in transplant kidneys: Correlations with clinical-Doppler parameters. Ultrasound Med Biol 2013;39:4-9.

9. Samir AE. The role and value of ultrasound elastography in the evaluation of thyroid nodules. Cancer Cytopathol 2016;124:765-766.

10. Gersak MM, Lupşor-Platon M, Badea R Ciurea A, Dudea SM. Strain Elastography (SE) for liver fibrosis estimation - which elastic score to calculate? Med Ultrason 2016;18:481-487.

11. Grenier N, Gennisson JL, Cornelis F, Le Bras Y, Couzi L. Renal ultrasound elastography. Diagn Interv Imaging 2013;94:545-550.

12. Dikici AS, Mihmanli I, Kilic F, et al. In Vivo Evaluation of the Biomechanical Properties of Optic Nerve and Peripapillary Structures by Ultrasonic Shear Wave Elastography in Glaucoma. Iran J Radiol 2016;13:e36849.

13. Liu BJ, Zhao CK, Xu HX, et al. Quality measurement on shear wave speed imaging: diagnostic value in differentiation of thyroid malignancy and the associated factors. Oncotarget 2017;8:4848-4959.

14. Detorakis ET, Drakonaki EE, Tsilimbaris MK, Pallikaris IG, Giarmenitis S . Real-time ultrasound elastographic imaging of ocular and periocular tissues: a feasibility study. Ophthalmic Surg Lasers Imaging 2010;41:135-141.

15. Unal O, Cay N, Yulek F, Taslipinar AG, Bozkurt S, Gumus M. Real-Time Ultrasound Elastographic Features of Primary Open Angle Glaucoma. Ultrasound Q 2016;32:333-337.

16. İnal M, Tan S, Yumusak EM, Şahan MH, Alpua M, Örnek K. Evaluation of the optic nerve using strain and shear wave elastography in patients with multiple sclerosis and healthy subjects. Med Ultrason 2017;19:39-44.

17. Batur M, Batur A, Çilingir V, et al. Ultrasonic Elastography Evaluation in Optic Neuritis. Semin Ophthalmol 2016;14:1-5.

18. Agladioglu K, Pekel G, Altintas Kasikci S, Yagci R, Kiroglu Y. An evaluation of ocular elasticity using real-time ultrasound elastography in primary open-angle glaucoma. Br J Radiol 2016;89:20150429.

19. Schneider M, Fuchshofer R. The role of astrocytes in optic nerve head fibrosis in glaucoma. Exp Eye Res 2016;142:4955.

20. Verdú E, Ceballos D, Vilches JJ, Navarro X. Influence of aging on peripheral nerve function and regeneration. J Peripher Nerv Syst 2000;5:191-208.

21. Burgoyne CF, Downs JC, Bellezza AJ, Hart RT. Threedimensional reconstruction of normal and early glaucoma monkey optic nerve head connective tissues. Invest Ophthalmol Vis Sci 2004;45:4388-4399. 